\title{
Phosphate Test 2.0
}

\author{
Etienne Stalder and Andreas Zumbuehl ${ }^{*}$
}

\begin{abstract}
The accurate measurement of the phosphate content of a liposomal suspension is important when working with differential scanning calorimetry. Standard phosphate tests date back several decades and require extended hands-on time. Here, we present a rapid version of a phosphate test taking advantage of microwaveassisted chemical digestion and multiwell plate reading technology allowing for the fast and accurate testing of many samples in parallel.
\end{abstract}

Keywords: Chemical digestion · Differential scanning calorimetry · Microwave digestion · Phosphate test . Phospholipids

\section{Introduction}

Phosphate tests are standard experiments in soft matter research of phospholipid vesicles. Each phospholipid typically contains one phosphate diester moiety. The chemical digestion of the lipids leads to orthophosphates that can be detected colorimetrically as metallo phosphates.

Several colored metallo complexes exist such as vanadomolybdophosphoric acid, molybdenum blue, or a phosphomolybdenum-malachite green complex. The vanadomolybdophosphoric acid complex was introduced more than 100 years ago for the rapid detection of phosphorus in steel. ${ }^{[1]}$ The yellowish color of the heteropoly acid was afterwards adapted for detection of the phosphorous concentration in biological materials ${ }^{[2]}$ and is now a standard method for assessing the phosphorus content in natural waters and wastewaters. ${ }^{[3]}$

The main phase transition temperature $\left(\mathrm{T}_{\mathrm{m}}\right)$ of a phospholipid bilayer membrane is an important parameter in soft matter research. At this point, the hydrophobic chains undergo a partial trans-to-gauche conformational change, which results in a transition from gel to liquid state. ${ }^{[4]}$ Using differential scanning calorimetry (DSC), the entropy and enthalpy changes of the transition can be directly extracted from the heat capacity profile of the phospholipid, provided the phospholipid concentration is accurately known. The typical samples used are liposomal systems, consisting of bi- or multilayer membrane vesicles. During the formulations of such suspensions, the phospholipids are passed through several solubilization and filtration steps. ${ }^{[5]}$ The phospholipid concentration in the final vesicle suspension therefore is different from the initial weighed-in powder, making an accurate phosphate test a prerequisite for the biophysical characterization of lipid membranes.

Phosphate tests for phospholipids have reached a very high level of accuracy. ${ }^{[6]}$ The steps involved are based on chemical digestion of phospholipids in open vessels. This leads to loss of solvent during the heating process and time-consuming volumetric measurements after chemical digestion. Also the throughput of the experiments is lowered and reasonably only a handful of experiments can be performed per day. Standard chemical digestion uses strong acids or combinations of acids and oxidizing agents. ${ }^{[3]}$ When moving into microwave-assisted chemical digestion, special care has to be taken when choosing the digestion mixture, in order to reduce the buildup of overpressure. ${ }^{[7]}$ The content of phospholipid to be tested has to be as low as possible, requiring a high sensitivity of the colorimetric detection method.

Many science departments are equipped with microwave ovens and multiwell plate readers. Taking advantage of these technologies, could the phosphate test not be performed much more rapidly and more hands-off? This article describes an updated version of the phosphate test.

\section{Experimental}

\section{Coloring Agent}

Ammonium metavanadate (125 mg, $1.1 \mathrm{mmol})(\geq 99 \%$, ACS reagent grade from Sigma-Aldrich) was dissolved in $60{ }^{\circ} \mathrm{C}$ ultrapure water $(20 \mathrm{~mL}$, Merck Millipore Synergy, $18.2 \mathrm{M} \Omega / \mathrm{cm}$ at $25{ }^{\circ} \mathrm{C}$ ). After

\footnotetext{
${ }^{\star}$ Correspondence: Prof. Dr. A. Zumbuehl

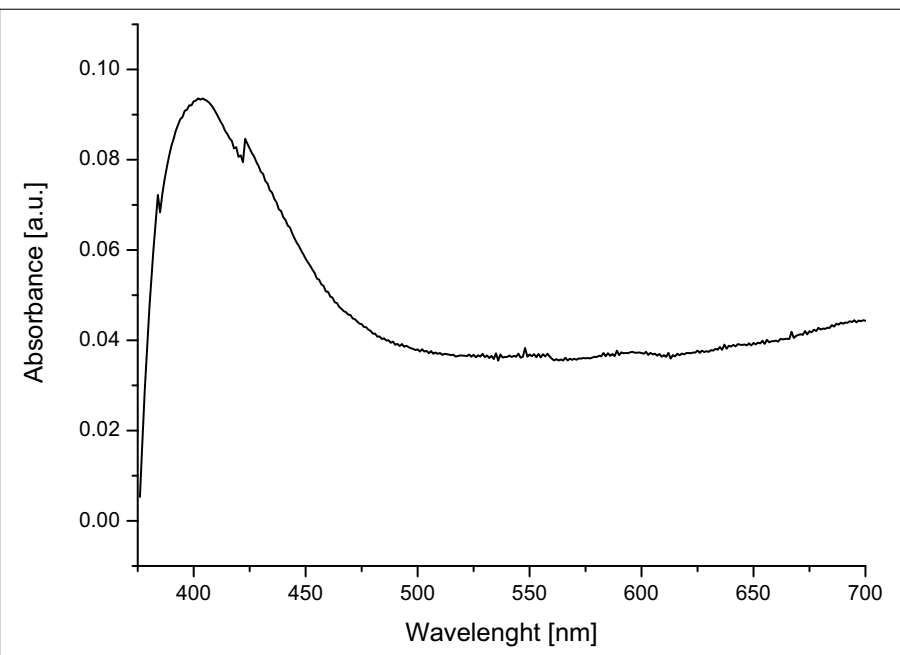

Fig. 1. UV-VIS spectrum of the yellow vanadomolybdophosphoric acid complex with an absorption maximum at $402 \mathrm{~nm}$. This maximum overlaps well with the 405 $\mathrm{nm}$ filter that comes standard in multiwell plate readers. 
complete dissolution of the complex the solution was cooled down to room temperature and $25 \mathrm{~mL}$ of $\mathrm{HNO}_{3}(65 \%$ Reag. ISO, Reg. Ph. Eur. grade from Honeywell) were added.

Ammonium heptamolybdate $(2.5 \mathrm{~g}, 2$ mmol, analytical grade from Merck) was dissolved in $60^{\circ} \mathrm{C}$ ultrapure water $(40 \mathrm{~mL})$, after complete dissolution of the complex the solution was cooled to room temperature. The ammonium metavanadate solution and the ammonium heptamolybdate solution were mixed together in a $100 \mathrm{~mL}$ volumetric flask, which was then filled up to the mark with ultrapure water.

The vanadomolybdophosphoric acid complex shows an absorption maximum at $402 \mathrm{~nm}$ (Fig. 1). This corresponds well with the standard $405 \mathrm{~nm}$ filter that is built into multiwell plate readers and is a strong financial advantage for using this yellow complex over other complexes that absorb at higher wavelengths.

\section{Calibration Curve}

A standard solution of $1 \mathrm{mM}$ potassium dihydrogenophosphate $(136.1 \mathrm{mg} / \mathrm{L}$, from Sigma-Aldrich) was prepared in ultrapure water. Solutions containing $0 \mu \mathrm{L}$, $10 \mu \mathrm{L}, 20 \mu \mathrm{L}, 50 \mu \mathrm{L}, 100 \mu \mathrm{L}, 150 \mu \mathrm{L}$, $200 \mu \mathrm{L}, 250 \mu \mathrm{L}, 400 \mu \mathrm{L}, 500 \mu \mathrm{L}, 750 \mu \mathrm{L}$, and $1000 \mu \mathrm{L}$ of the standard solution $(0$ $\mu \mathrm{M}-200 \mu \mathrm{M})$ were each complemented to $2.5 \mathrm{~mL}$ with ultrapure water. Then $500 \mu \mathrm{L}$ of a mixture (3/1 v/v) of $\mathrm{HNO}_{3}(65 \%$ Reag. ISO, Reg. Ph. Eur. grade from Honeywell) and $\mathrm{H}_{2} \mathrm{SO}_{4}$ (95-97\% Reag. ISO, Reg. Ph. Eur. grade from Honeywell), $1 \mathrm{~mL}$ of coloring agent and $1 \mathrm{~mL}$ of $\mathrm{NaOH}$ solution (10 M, $40 \mathrm{~g} \mathrm{NaOH} / 100 \mathrm{~mL} \mathrm{H} \mathrm{O}, \mathrm{NaOH}$ from Reactolab SA) were added and the solution was mixed by vortexing and left standing for 10 minutes.

The standard solution was poured into a solution basin (Biologix). The standards were then transferred to 8 rows, $300 \mu \mathrm{L}$ each of a 96 microwell plate (Nunc-
Immuno plate F96 Polysorb) and the absorbance was measured at 405 in a plate reader (Multiskan FC96 from Thermo Scientific).

A highly reproducible linear calibration curve was obtained (Fig. 2). Recalibration is not strictly required, nonetheless, the quick assay proposed here allows for rapid calibrations for quality control reasons.

\section{Phospholipid Suspensions}

Egg-PC (5.97 mg, $7.9 \mathrm{mmol}$, from Avanti Polar Lipids) was dissolved in $\mathrm{CHCl}_{3} \quad(99 \%$ reagent grade from Honeywell). Then the organic solvent was removed under reduced pressure while the round bottom flask was constantly turned in order to form a continuous phospholipid film on the wall of the glass vessel. The film was hydrated with $5 \mathrm{~mL}$ of ultrapure water at room temperature.

The sample was first cooled down in a liquid nitrogen bath and then thawed in a water bath $\left(40{ }^{\circ} \mathrm{C}\right)$. Freeze-thawing was repeated 5 times in order to form multilamellar vesicles.

\section{Sample Analysis}

The following protocol was used for measuring the phospholipid content of vesicle suspensions (Fig. 3):

1) $200 \mu \mathrm{L}$ of a phospholipid vesicle suspension was added to a $0.5-2 \mathrm{~mL} \mathrm{mi-}$ crowave vial (Biotage).

2) $500 \mu \mathrm{L}$ of a mixture $(3 / 1 \mathrm{v} / \mathrm{v})$ of $\mathrm{HNO}_{3}(65 \%$ Reag. ISO, Reg. Ph. Eur. grade from Honeywell) and $\mathrm{H}_{2} \mathrm{SO}_{4}$ (9597\% Reag. ISO, Reg. Ph. Eur. grade from Honeywell) were added to the vial.

3) The vial was sealed and heated to $180{ }^{\circ} \mathrm{C}$ for 20 minutes in a microwave (Biotage Initiator).

4) The vial was cooled down and carefully opened.

5) $2.3 \mathrm{~mL}$ ultrapure water were added.

6) $1 \mathrm{~mL}$ vanadium molybdate solution was added and the vial was shaken.
7) $1 \mathrm{~mL} \mathrm{NaOH}$ solution $(10 \mathrm{M})$ was added and the vial was shaken.

8) The solutions were left standing for $10 \mathrm{~min}$.

9) The solution was mixed and poured into a solution basin (Biologix).

10) The sample was pipetted into a 96 well plate (Nunc-Immuno plate F96 Polysorb) using a multi-channel pipette ( 8 times $300 \mu \mathrm{L}$ ).

11) The absorbance was measured at $405 \mathrm{~nm}$ using a plate reader (Multiskan FC 96 from Thermo Scientific).

During the microwave heating, the 310 $\mu$ mol of lipid and the digestion solution used in this example build up a pressure

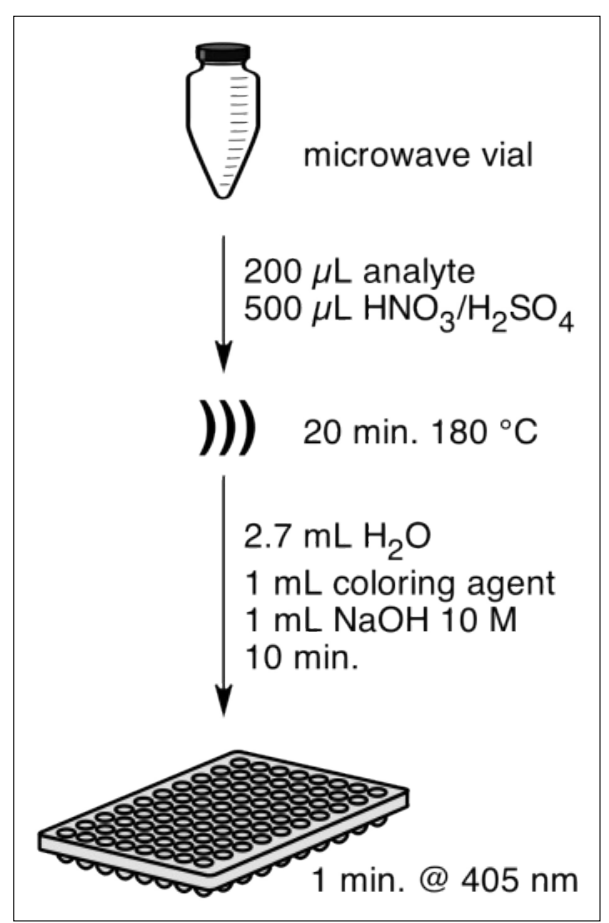

Fig. 3. Flow diagram of a microwave assisted chemical digestion of a phospholipid vesicle suspension followed by colorimetric orthophosphate detection using a multiwell plate reader.

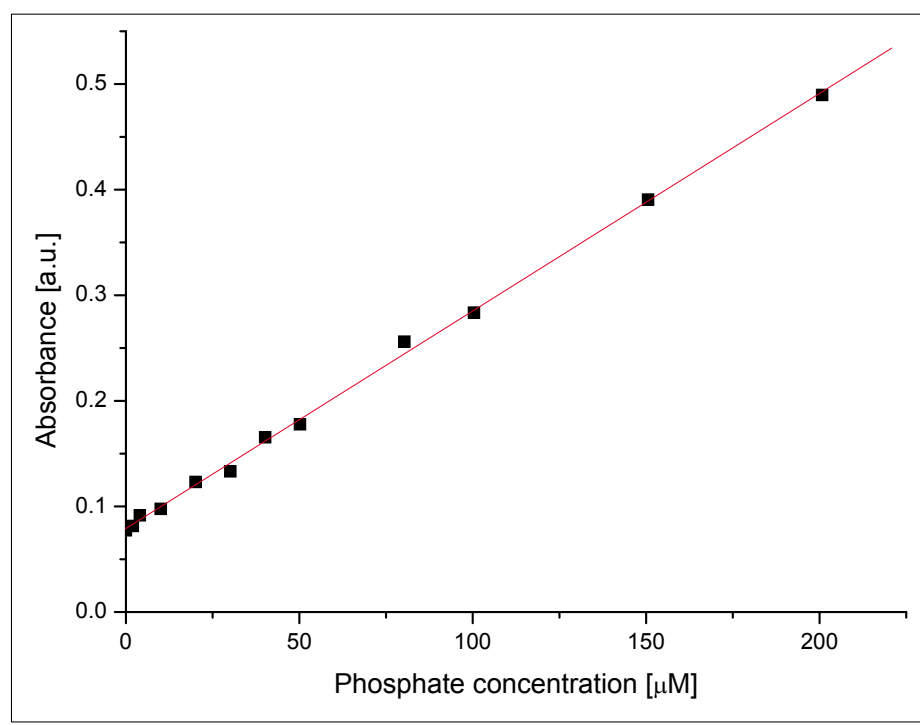

Fig. 2. The calibration curve can be fitted linearly by the equation: $y=0.0021 x$ +0.0791 . The coefficient of determination is $R^{2}=0.9985$.

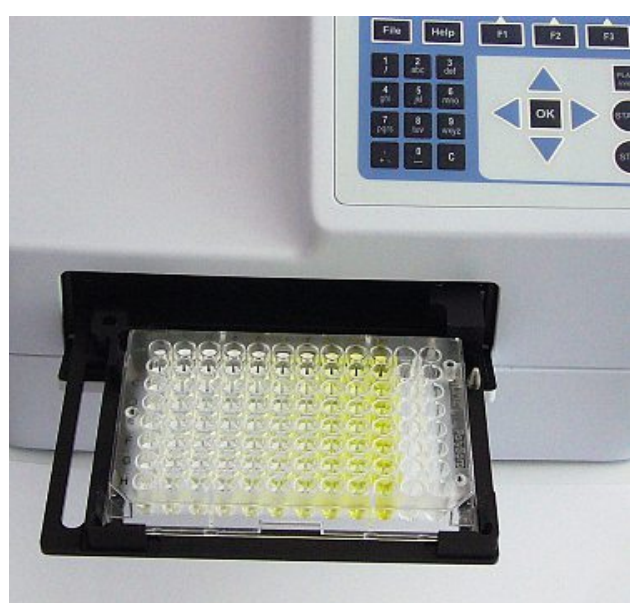

Fig. 4. Convenient measurement of an orthophosphate standard curve using a multiwell plate reader. 
Table 1. Sample dataset of four individual measurements of a phospholipid vesicle suspension. The mean value amounts to an orthophosphate recovery of $97.6 \%$.

\begin{tabular}{|c|c|c|c|}
\hline Sample & Weighed in $[\mu \mathrm{M}]$ & Measured $[\mu \mathrm{M}]$ & Recovery $[\%]$ \\
\hline 1 & 1550 & 1509 & $97.4 \%$ \\
\hline 2 & 1550 & 1610 & $103.9 \%$ \\
\hline 3 & 1550 & 1476 & $95.2 \%$ \\
\hline 4 & 1550 & 1455 & $93.9 \%$ \\
\hline
\end{tabular}

of 5-6 bar (typically a microwave oven tolerates up to 18 bar). After cooling, the overpressure is no longer present.

\section{Results}

Table 1 shows the results of several individual experiments from a phospholipid vesicle suspension. The measured data lie within an error of $6 \%$, which is comparable to other published methods. ${ }^{[7]}$ A clear advantage of the method described here is the fact that several individual experiments can be run in parallel (Fig. 4). After four runs, the accuracy can be increased to $>97 \%$ orthophosphate recovery.

\section{Conclusions}

We have presented an updated version of a 100 year-old phosphate test protocol. Hands-free machine-based techniques allow for a high throughput of test reactions. The rapid test gives results within $6 \%$ accuracy, a value that can be lowered by parallel experiments that are feasible at low additional experimental effort.

\section{Acknowledgements}

The authors thank the Swiss National Science Foundation (PP00P2_138926/1), the University of Fribourg and the NCCR Chemical Biology for financial support.

Received: July 3, 2013
[1] G. Misson, Chem.-Ztg. 1908, 53, 633.

[2] R. A. Koenig, C. Johnson, Ind. Eng. Chem. Anal. Ed. 1942, 14, 155.

[3] L. S. Clesceri, A. E. Greenberg, A. D. Eaton, 'Standard Methods for the Examination of Water and Wastewater', 20th ed., APHA American Public Health Association, 1998.

[4] T. Heimburg, 'Thermal Biophysics of Membranes', Wiley-VCH Verlag, Weinheim, 2007.

[5] P. Walde, Encyclopedia of Nanoscience and Nanotechnology 2004, 9, 43 .

[6] R. Sauder, J. Seelig, A. Ziegler, in 'Methods in Molecular Biology', Ed. Ü. Langel, Humana Press, Totowa, NJ, 2010, pp. 129-155.

[7] M. Wu, Q. Ge, Y. Gao, K. Chen, Iran. J. Chem. Chem. Eng. 2012, 31, 15 . 